\title{
AMMI VISNAGA IN THE TREATMENT OF THE ANGINAL SYNDROME*
}

\author{
BY \\ G. V. ANREP, G. S. BARSOUM, M. R. KENAWY, AND G. MISRAHY \\ From the Physiological Laboratory and the University Hospital, Cairo, Egypt
}

Received August 28, 1945

The plant Ammi Visnaga, known in Arabic as “ Khella," grows wild in the Eastern Mediterranean countries and in Arabia. The decoction of its dried seeds is much used by the population and is frequently prescribed by local physicians as a diuretic and antispasmodic in cases of ureteral stones. Of the several crystalline substances isolated from the seeds, quantitatively the most important are a substance called khellin $\left(\mathrm{C}_{14} \mathrm{H}_{12} \mathrm{O}_{5}\right)$ and a monoglucoside $\left(\mathrm{C}_{19} \mathrm{H}_{20} \mathrm{O}_{5} 2 \mathrm{H}_{2} \mathrm{O}\right)$. Almost the entire activity of Ammi Visnaga is due to the khellin.

Khellin was first prepared in an impure form by Mustapha (1879) and again by Malosse (1881). Fantl and Salim (1930) isolated and purified both khellin and the glucoside; they determined their respective properties and composition, established methods for their separation, and suggested the most likely structural formulæ. The pharmacognosical features of the two substances were studied by Fahmy (1931). The final determination of their structural formulæ was made by Malik (1932) for khellin and by Hassan (1932) for the glucoside, both working under the direction of Prof. R. W. West of Cairo University. In 1934 the decoction and the tincture of Ammi Visnaga were included in the Egyptian Pharmacopoia. Pharmacologically the action of khellin was studied by Samaan (1932) who showed that it relaxes all the visceral smooth muscles by direct action on the muscle fibres. Samaan also suggested changing the name of khellin to visamin. We prefer the original name since it is free from the implication of containing an amino group. Preliminary experiments of Anrep and Misrahy (1945) showed that khellin is a strong coronary vasodilator.

The object of the present research was to investigate by physiological methods the action of khellin on the cardiovascular system with special reference to the coronary circulation and the heart muscle, and also to study its action clinically on patients suffering from angina pectoris and coronary thrombosis.

\section{Physiological Part}

The experiments were made on dogs, using the heart-lung preparation and the whole animal. The coronary blood was collected from the coronary sinus through a Morawitz cannula and the blood flow was registered by means of a small volume recorder. The khellin at our disposal was a crystalline product of a constant melting-point $\left(153^{\circ} \mathrm{C}\right.$.). We should like to thank Prof. Samaan for the supply of a small sample of the active material for our preliminary experiments. The rest of the experiments and almost all the clinical observations were made with khellin prepared in the Physiological Laboratory by a modified method of Fantl and Salim. The results of our observations are best presented by a description of a few typical experiments.

\section{Experiments on the Heart-Lung Preparation}

Experiment 1. Heart-lung preparation; blood pressure $100 \mathrm{~mm}$. $\mathrm{Hg}$.; cardiac output 500 c.c. per minute; temp. $36.5^{\circ} \mathrm{C}$. The coronary sinus outflow was steady at $41-42$ c.c. per minute. On administration of $10 \mathrm{mg}$. of khellin the coronary blood flow rapidly increased to

*A preliminary communication was published in the Gazette of the Faculty of Medicine, Cairo, 1945, 13, 39, by Kenawy and Barsoum. 
120 c.c. per minute. The blood flow remained increased up to the end of the experiment, over 3 hours, fluctuating between 110 and 130 c.c. per minute. The total amount of blood in the circulation was about 1 litre and the weight of the heart $85 \mathrm{~g}$. The record obtained in this experiment is reproduced in Fig. 1.

Experiment 2. Blood pressure $95 \mathrm{~mm}$. Hg.; cardiac output 450 c.c. per minute; temp. $37^{\circ} \mathrm{C}$. The coronary blood flow was steady at 33 c.c. per minute. After administration of $1 \mathrm{mg}$. of khellin dissolved in 5 c.c. of blood it increased to 50 c.c. per minute; after another $1 \mathrm{mg}$. it became 70 c.c. per minute. A further administration 10 minutes later of $3 \mathrm{mg}$. increased the flow to 100 c.c. per minute. The heart rate and the systemic output remained constant while the increase in the coronary circulation was maintained to the end of the experiment. The amount of blood in circulation was about 1 litre and the weight of the heart $74 \mathrm{~g}$. A record of this experiment is given in Fig. 2.

Experiment 3. This experiment was made in order to determine the minimal active dose of

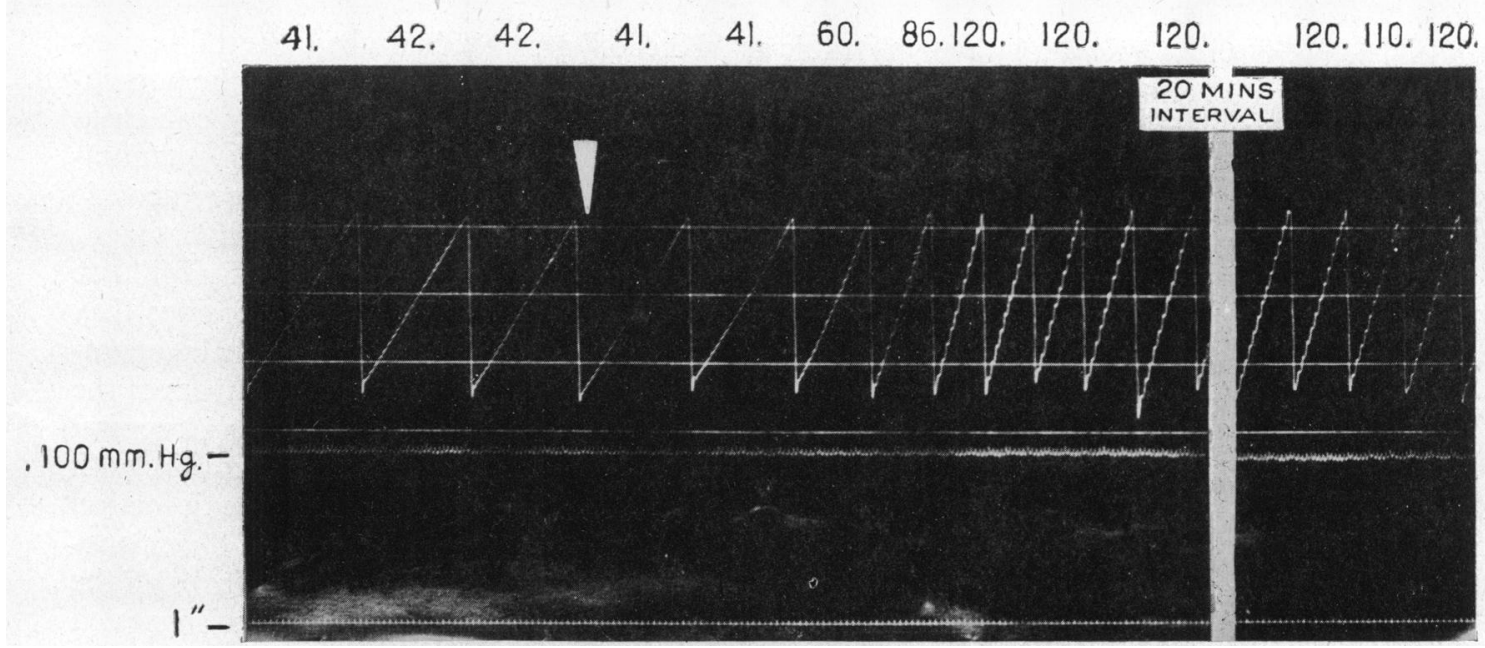

Fig. 1.-Expt. 1. Heart-lung preparation. Shows outflow from coronary sinus registered by volume recorder calibrated in 5 c.c. The figures added above the smoked paper give the flow in c.c. per minute. Blood pressure and time in seconds are recorded below. The arrow indicates injection of $10 \mathrm{mg}$. khellin.

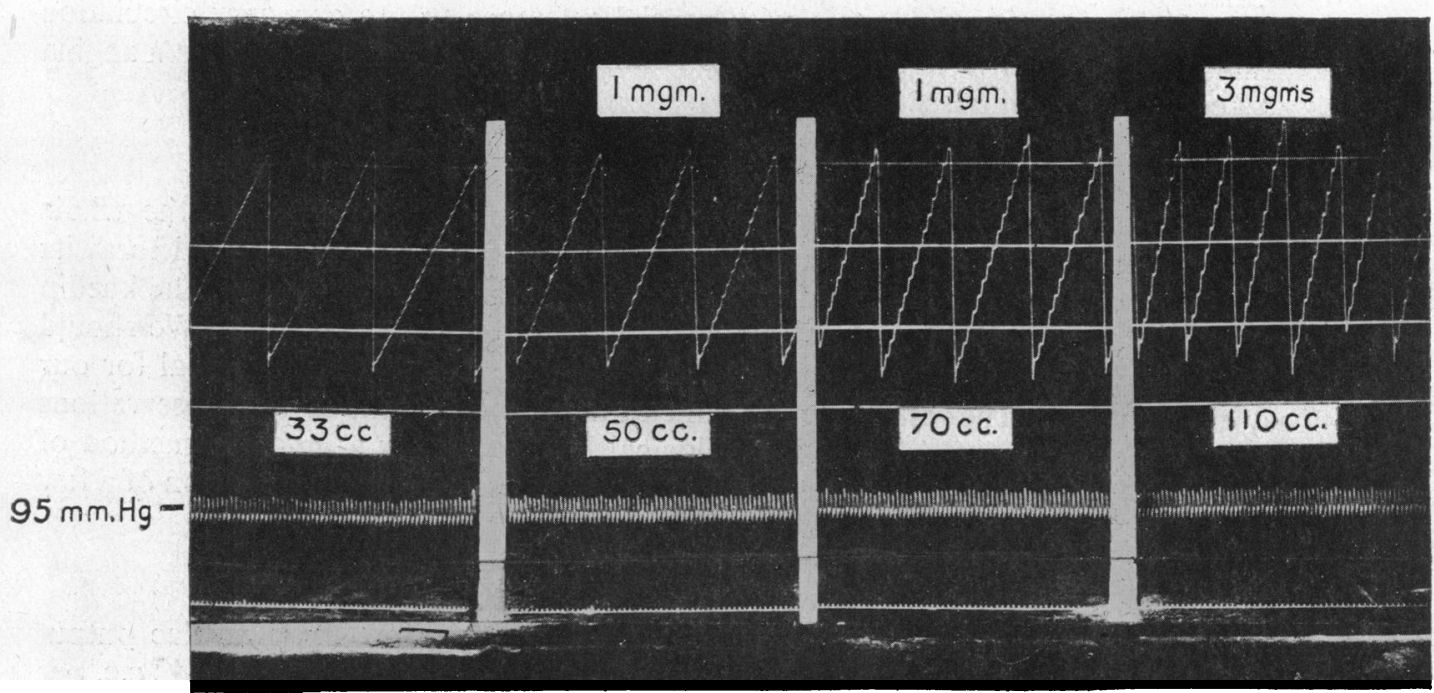

FIG. 2.-Expt. 2. Heart-lung preparation. Shows effect of small doses of khellin (upper figures) on coronary flow, registered by volume recorder and given in c.c. per minute in lower figures. The records were taken at intervals of 10 minutes. 
khellin that would dilate the coronary blood vessels. The conditions of the experiment were like those of experiments 1 and 2 . The amount of blood in circulation was measured as exactly as possible. The khellin was administered in successive small doses at intervals of 5 to 10 minutes.

\begin{tabular}{c|c|c}
\hline $\begin{array}{c}\text { Mg. of khellin } \\
\text { administered }\end{array}$ & $\begin{array}{c}\text { Approximate } \\
\text { concentration }\end{array}$ & $\begin{array}{c}\text { Coronary blood } \\
\text { flow in c.c. per } \\
\text { minute }\end{array}$ \\
\hline None & $\begin{array}{c}\text { None } \\
0 \cdot 4\end{array}$ & $\begin{array}{c}44-46 \\
\text { in } 2,500,000\end{array}$ \\
$0 \cdot 4$ & 1 in $1,250,000$ & $47-49$ \\
$0 \cdot 8$ & 1 in 625,000 & $56-57$ \\
$3 \cdot 2$ & 1 in 208,000 & $83-85$ \\
$3 \cdot 2$ & 1 in 125,000 & $120-130$ \\
& & $160-180$ \\
\hline
\end{tabular}

It can be seen from the above and other similar experiments on the dog that the minimal active concentration of khellin in the heart-lung preparation is about 1 in $2,000,000$. With concentrations of the order of 1 in 200,000 the coronary blood flow increases 3 to 4 times the initial volume. The action of khellin, although very considerable, is less than that of amyl nitrite, but it has the advantage of being much more prolonged. We should like to add that the isolated perfused rabbit's or cat's heart is not a suitable object for the study of the coronary dilator action of khellin. , As with many other substances the results obtained are indefinite and inconclusive.

Samaan (1932) reports that in high concentrations khellin causes a weakening of the isolated perfused frog's and rabbit's heart. In repeated experiments on the heart-lung preparation no such effect was observed. Gradual administration of doses as high as $100 \mathrm{mg}$. causes no change in the heart volume, which is generally recognized as the best measure of cardiac fitness (Fig. 3). It is, therefore, obvious that doses many times greater than those causing a conspicuous coronary vasodilatation have no injurious effects on the heart muscle. Cardiograms taken before and after administration of khellin were found to be identical in all respects. The pulmonary blood pressure and the rate of the denervated heart were not affected.

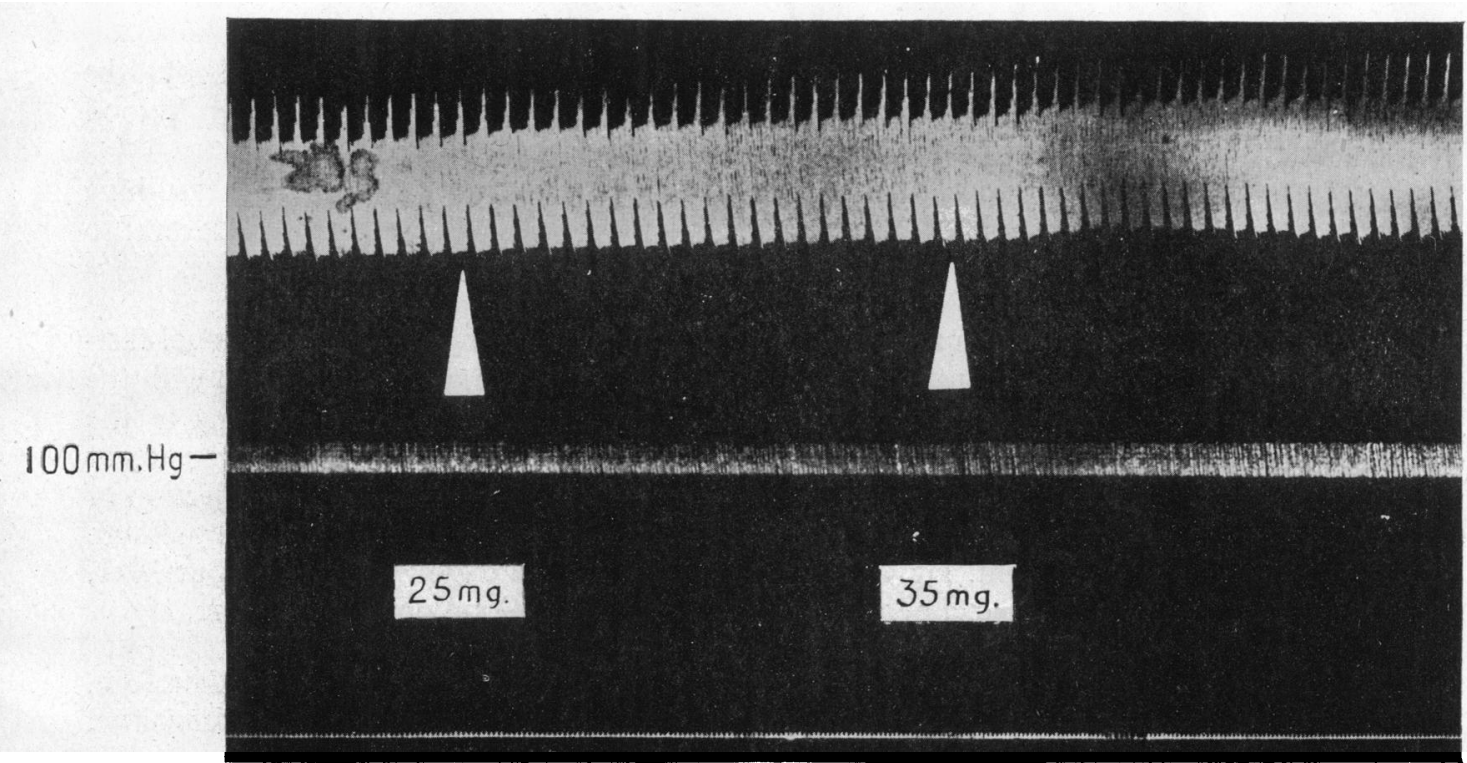

FIG. 3.-Heart-lung preparation. Effect of khellin on the heart volume; 25 and $35 \mathrm{mg}$. of khellin were administered at first and second arrow respectively. 
EXPERIMENTS ON THE WHOLE ANIMAL

According to the observations of Samaan (1932) intravenous injections of khellin into the whole animal lead to a temporary fall of the arterial blood pressure, to a slowing of the heart rate which is vagal in origin, and to some acceleration of the respiration. Our experiments on the whole animal were made on dogs anæsthetized with chloralose $(0 \cdot 075-0 \cdot 1 \mathrm{~g}$. per $\mathrm{kg}$.) or medinal $(0 \cdot 22 \mathrm{~g}$. per $\mathrm{kg}$.). The blood pressure was measured in the carotid artery while the respiration was recorded by a Marey's tambour which was placed on the sternum. Intravenous injections of khellin produced effects similar to those described by Samaan but only on rapid administration of large doses. Immediately after a rapid injection of $20-30 \mathrm{mg}$. the blood pressure drops to about $50 \mathrm{~mm}$. $\mathrm{Hg}$., the heart beats considerably slower, and the respiration is momentarily arrested. The entire effect lasts for only a short time; within a minute or two the general blood pressure, heart rate, and respiration return to normal. Slow intravenous injections at the rate of $2 \mathrm{mg}$. per 20-30 seconds can be continued for a long time without ill effects (Fig. 4). The maximal total dose so injected was $10 \mathrm{mg}$. per kilogram.

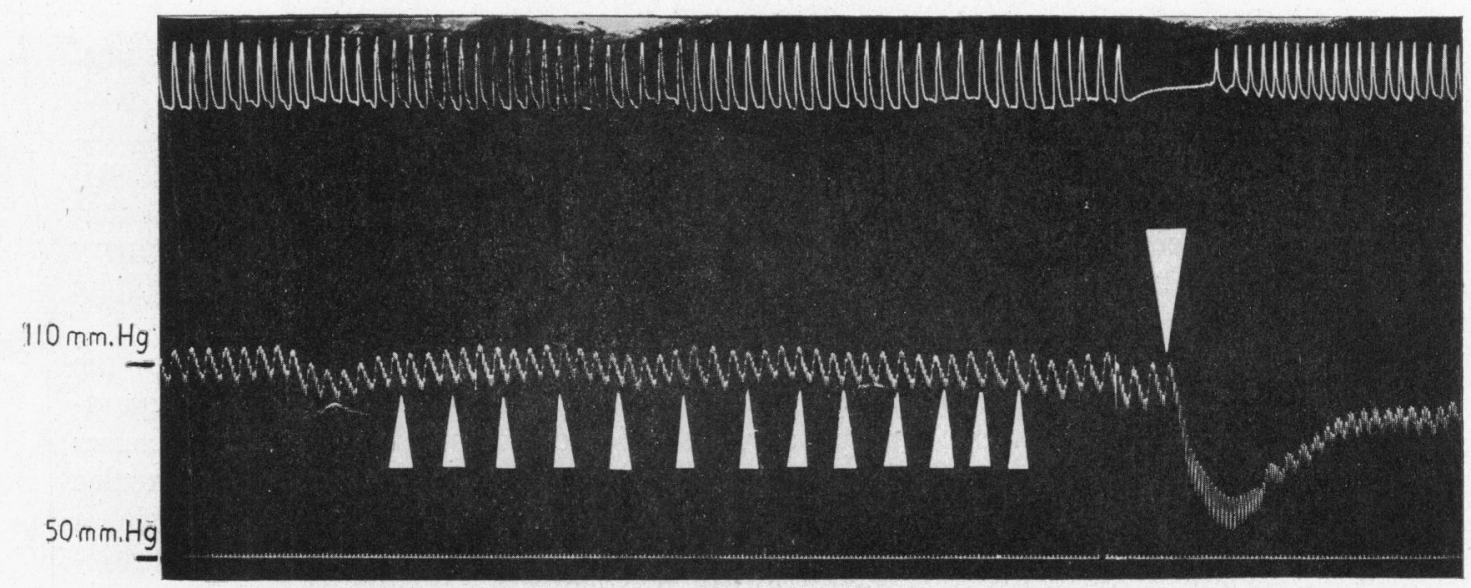

FIG. 4.-Effect of gradual and of rapid intravenous injections of khellin on the blood pressure and respiration of the whole animal. The end of injections of each $2 \mathrm{mg}$. is marked by an arrow pointing upwards. A rapid injection of $20 \mathrm{mg}$. was made at the last arrow pointing downwards. Time in seconds, arterial blood pressure, and respiration from below upwards.

It follows from these experiments that subcutaneous and intramuscular injections should be well tolerated. Doses of 40-50 mg. per kilogram cause a prolonged fall of the general blood pressure due to peripheral vasodilatation mainly of the splanchnic area.

The coronary vasodilator action of khellin can be observed not only in the heart-lung preparation but also in the whole animal. Experiment 4 is selected from amongst several to illustrate the effect.

Experiment 4. Dog, $11 \mathrm{~kg}$., anæsthetized with chloralose and injected with chlorazol-fastpink as anticoagulant. To prevent loss of blood the coronary cannula is connected with the jugular vein. It is opened to the volume recorder only during the measurements of the coronary blood flow. Before administration of khellin the coronary blood flow was steady at 27 c.c. per minute. After injection of $10 \mathrm{mg}$. the flow increased to 50 c.c. After injection of another $10 \mathrm{mg}$. the flow reached 80 and then 100 c.c. per minute. The general blood pressure remained unchanged at $105 \mathrm{~mm}$. Hg. Towards the end of the experiment, one hour later, the coronary blood flow was 90 c.c. per minute and the arterial blood pressure, $95 \mathrm{~mm}$. $\mathrm{Hg}$.

Khellin exerts no stimulating effect on the sympathetic nervous system. It is, therefore, unlikely that its coronary vasodilator action is similar in nature to that produced by adrenaline. As with other smooth muscles it acts directly on the muscle fibres of the blood vessels. The apparently selective action of khellin on the coronary blood vessels is due to their much greater sensitivity to the drug as compared with the systemic blood vessels. 


\section{Clinical Part}

As a clinical trial khellin was given to 46 patients of whom 38 had angina pectoris of effort or decubitus or both, and 8 had coronary thrombosis. The cases of angina pectoris were graded as mild, moderate, or severe. Those subject to occasional pain on effort were classed as mild; those with more frequent pain on effort and occasionally apart from it, who used trinitrine regularly, as moderate; those with frequent pain on slight effort or at rest and especially at night, who used trinitrine freely, as severe. On this basis, 8 cases were mild, 17 moderate, and 13 severe. There were 34 men and 4 women, and their ages ranged from 35 to 66 years. The duration of anginal symptoms was 3-12 years in 14 cases, $1-2$ years in 17, and less than a year in 7. Hypertension was present in 15 cases and diabetes in 7 . The Wassermann reaction was negative in all but one case. Abnormal electrocardiograms were recorded in 17 cases, and enlargement of the heart and aorta was found in 4 cases. Of the 8 cases of coronary thrombosis, 6 had recurrent attacks of pain, and 2 had dyspnœa during the period of complete rest following the onset of symptoms.

The subjective effects of the drug were recorded in each case. In some, electrocardiographic changes provoked by graded exercise were recorded before and after treatment. Exercise tolerance tests were performed whenever the patient's condition permitted. As a control, injections free from khellin or containing a much reduced dose were substituted without the patient's knowledge.

Method of Administration and Dosage. The following preparations were tried.

1. Purified liquid extract containing $40 \mathrm{mg}$. of active principle per c.c.; dose 30-60 minims in water with meals.

2. Pills each containing $25 \mathrm{mg}$; d dose $2-3$ pills thrice daily after food.

3. Solution of $60 \mathrm{mg}$. per c.c. by intramuscular injection; dose 1-2 c.c. daily or on alternate days, and for the treatment of individual attacks.

Doses of 10-30 mg. per day by injection were tried first and found to be ineffective. A dose of $60 \mathrm{mg}$. a day gave encouraging results; and $90-120 \mathrm{mg}$. a day still better. Single doses of $150-200 \mathrm{mg}$. were given to healthy volunteers without ill effect. An average effective dose proved to be $90 \mathrm{mg}$. a day. The injections caused slight and transient local pain. The average oral dose was $40 \mathrm{mg}$. thrice daily.

\section{Anginal Group}

The response to khellin was arbitrarily classed as good, moderate, or negative; good when the anginal attacks ceased altogether or became very infrequent and mild, moderate when they diminished in frequency and severity, and negative otherwise. On this basis the results are summarized in Table I. The duration of observation and treatment varied from 3-9 months, being 6 months or longer in half, excluding those classed as failures where treatment was abandoned earlier.

TABLE I

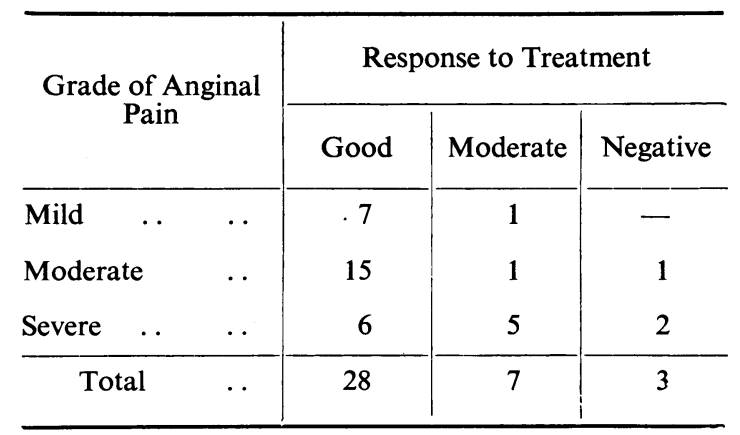

Continuous Treatment. Oral administration of the liquid extract or pills alone was tried in 13 cases, intramuscular injections alone in 9, and both methods combined in 16 . The 13 cases treated by oral doses of $120 \mathrm{mg}$. of khellin a day all showed a good response. Given 
by mouth, the drug required 1-3 days to reach its full effect. The severity of the attacks was reduced before the frequency. If the drug was discontinued for a few days the attacks reappeared, sometimes in milder form.

Of 9 cases treated by injections alone, in doses of $90 \mathrm{mg}$. daily or $120 \mathrm{mg}$. on alternate days, 8 showed a good response. On cessation of the injections, or on substitution of inert injections as a control, the anginal attacks recurred, and restarting the injections again resulted in relief. The effect of each injection appeared to last 24-36 hours.

The 16 patients treated by a combination of oral and intramuscular khellin were mostly classed as severe cases. The injections and oral doses were given on alternate days. This combined treatment seemed more effective in severe cases, though two so treated failed to respond. One of these also had carcinoma of the stomach, and the other, after several days of frequent anginal attacks, died suddenly from coronary thrombosis. The third failure was treated orally for three weeks without effect.

Treatment of Individual Attacks. Patients were given liquid extract of khellin to take in the attacks, and nearly all reported favourably, especially in the case of more prolonged attacks of pain occurring apart from effort. In a few cases, we had the opportunity of giving injections during an attack and relief followed within a few minutes, rather more slowly than after trinitrine tablets.

Objective Tests. In some cases electrocardiograms before and after a standard exercise test of stepping on a chair $40 \mathrm{~cm}$. high at a rate of 30 times a minute were recorded. Later,

I
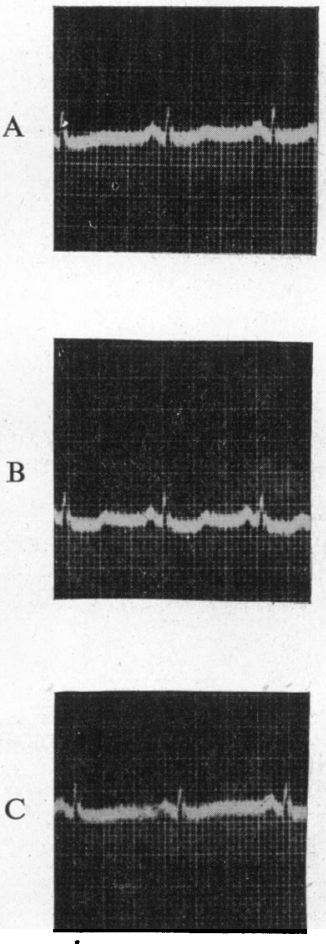

II
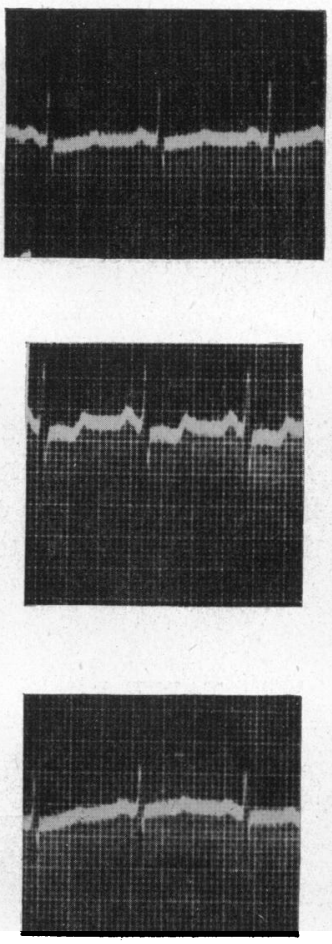

III
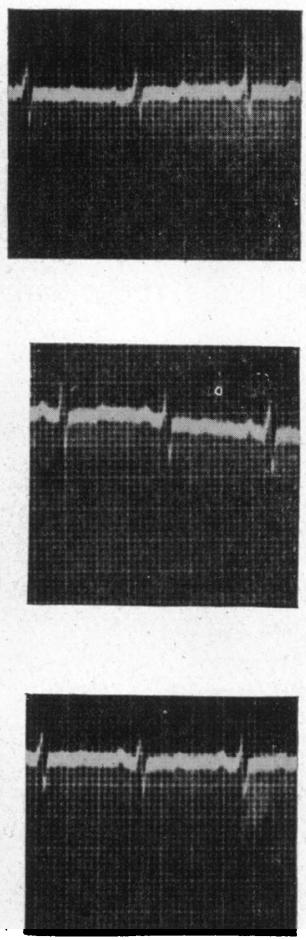

Fig. 5.-Effect of khellin on the electrocardiogram taken after standard exercise. (A) at rest; (B) after exercise; (C) taken on the following day, after a similar exercise, and 30 minutes after an intramuscular injection of $90 \mathrm{mg}$. of khellin.

the same exercise was performed 30 minutes after an injection of khellin, and the cardiogram was again recorded. Four cases showed S-T depression after a test exercise; in three of these, an injection of $90 \mathrm{mg}$. of khellin prevented the occurrence of S-T depression after the same exercise (Fig. 5), and in the fourth S-T depression was less conspicuous. In all patients tested, the exercise tolerance, as measured by the exercise described, increased after khellin. 
Side Effects. A few patients complained of insomnia after the first few doses, one complained of pain and fullness in the head, and two of dyspepsia after oral administration. The blood pressure, pulse rate, and respiration were unaffected by doses up to $120 \mathrm{mg}$. of khellin. The clotting time and bleeding time were also unaffected.

\section{Coronary Thrombosis Group}

Khellin was given orally or by injection in doses of 90-120 mg. daily for 2-5 weeks after the onset of coronary thrombosis in 8 cases, in 6 of which there were recurrent anginal attacks during the period of recumbency. The drug was also given with morphine at the onset of symptoms. It was well tolerated and as far as could be judged it relieved the spasmodic anginal attacks that followed the initial attack of pain. The variability of the symptoms after coronary thrombosis makes it difficult to assess the effect of drug treatment, and the small number of cases yet treated is insufficient to warrant any definite conclusions as to the value of the treatment. It seems rational to give a coronary vasodilator that does not lower general blood pressure or affect the heart rate, with a view to preventing any associated coronary vasoconstriction, and thus minimizing the area of cardiac infarction.

\section{ConClusions}

Physiological experiments show that khellin is an effective coronary vasodilator in doses insufficient to cause any general fall in blood pressure. A preliminary clinical trial has shown that the drug may be given safely and without toxic effects in the doses prescribed. Khellin has advantages over the nitrites and other reputed vasodilators in that it has a selective action on the coronary vessels, and effective doses need not, therefore, lower systemic blood pressure. Its action is slower but more prolonged than that of the nitrites. It may be given in the form of continuous treatment to abolish or reduce the frequency and severity of anginal attacks, or to relieve individual severe attacks of pain. It is no simple matter to assess the value of a drug in the continuous treatment of angina pectoris, as Evans and Hoyle (1933) have shown, for they found that even a placebo might produce subjective improvement in a surprisingly large proportion of cases. This preliminary clinical trial, following physiological experiments, seems sufficiently favourable to justify a further and more extensive therapeutic test of khellin in angina pectoris and coronary occlusion.

\section{SUMMARY}

Khellin, the active principle of Ammi Visnaga, has been tested physiologically in dogs, both on the heart-lung preparation and on the whole animal, in regard to its effect on the heart and coronary circulation. It was found to be an effective vasodilator with a selective action on the coronary vessels, so that coronary flow was increased by doses insufficient to lower the general blood pressure.

A clinical trial of khellin in 38 cases of angina pectoris and in 8 cases of coronary thrombosis is reported. Continuous treatment, by the oral or intramuscular routes or by both combined, gave favourable results in 35 out of 38 cases of angina pectoris. The drug was given continuously for several weeks to eight patients after coronary thrombosis and appeared to act favourably, but no definite conclusions could be reached as to its value in this respect.

\section{REFERENCES}

Anrep, G. V., and Misrahy, G. (1945). Gaz. Faculty Med., Cairo, 13, 33.

Evans, W., and Hoyle, C. (1933). Quart. J. Med., N.S., 2, 311.

Fahmy, I. R., and Keiy, M. A. (1931). Report of Pharmaceut. Soc. Egypt, vol. 3.

Fantl, P., and Salim, S. I. (1930). Biochem. Z., 226, 166.

Hassan, M. K. (1932). Thesis, Cairo.

Malik, W. S. (1932). Ibid.

Malosse, T. (1881). Thèse, Montpellier.

Mustapha I. (1879). C.R. Acad. Sci., Paris, 89, 442.

Samaan, K. (1932). Quart. J. Pharm. and Pharmacol., 5, 6. 